\title{
RBC ANTIBODIES IN PREGNANCY AND GENERAL POPULATION- A DESCRIPTIVE STUDY AT A QUATERNARY CENTRE
}

\author{
Sonika Gupta1, Deepak Kumar², Rita Mhaskar ${ }^{3}$
}

${ }_{1}^{1}$ Clinical Fellow, High Risk Pregnancy, Department of Obstetrics and Gynaecology, Manipal Hospital, Bangalore, Karnataka, India. ${ }^{2}$ Clinical Fellow, Department of Paediatric Cardiology, Manipal Hospital, Bangalore, Karnataka, India. ${ }^{3}$ Consultant, Manipal Hospital, Bangalore, Karnataka, India.

ABSTRACT
BACKGROUND
It is important to identify all RBC antibodies in pregnancy to determine whether there is a risk of haemolytic disease of newborn
and to facilitate cross matching of maternal blood if an emergency transfusion is required at delivery.
Aims and Objectives- (1) To measure the prevalence of RBC antibodies in pregnant women coming to a quaternary care centre at
Bangalore, (2) To describe the maternal and perinatal outcome in those who are found to be RBC antibody positive and (3) To
compare the prevalence of antibodies in pregnant ladies with prevalence in patients other than pregnant women coming to the
hospital.

\section{MATERIALS AND METHODS}

This cross-sectional study was conducted in Manipal Hospital, Bangalore from 1st October, 2012 to 30th August, 2013 on antenatal patients and other patients from other departments on whom blood grouping and antibody screening has been done. After proper history, blood samples were collected in EDTA vials and were centrifuged at 2,000 rpm for 5 minutes and plasma separated immediately and tested for grouping and presence of antibodies.

\section{RESULTS}

8128 patients which included 1030 (12.67\%) pregnant patients and 7098 (87.32\%) non-pregnant patients were screened for antibodies during this period with positivity of $3.3 \%$ in pregnancy and $0.8 \%$ in other patient population. Anti D was the predominant antibody found in $81 \%$ pregnant patients with anti $\mathrm{E}$ and Anti Le ${ }^{\mathrm{a}}$ in $6.1 \%$ each and anti $\mathrm{C}$ and anti $\mathrm{K}$ in $3 \%$ each. Anti D was positive in $17.7 \%$ of the non-pregnant group followed by Anti Lea $14.5 \%$, anti M $11.3 \%$ and anti E 9.7\%. Except two patients, all other patients and their newborns in the positive group did not have any other significant morbidity.

\section{CONCLUSION}

Despite prophylactic use of $\mathrm{Rh}$ immunoglobulins, anti-D is still a common antibody identified as the major cause of alloimmunisation. The incidence of non-Rh antibodies is also high especially in the non-pregnant group and this increasing trend may lead to increase in incidence of HDFN and transfusion related reactions in the future.

\section{KEY WORDS}

RBC Antibodies, Pregnancy, General Population.

HOW TO CITE THIS ARTICLE: Gupta S, Kumar D, Mhaskar R. RBC antibodies in pregnancy and general population- a descriptive study at a quaternary centre. J. Evolution Med. Dent. Sci. 2019;8(05):294-297, DOI: 10.14260/jemds/2019/65

\section{BACKGROUND}

RBC antibodies are immunoglobulins associated with RBC antigens. Isoagglutinin to the $\mathrm{ABH}$ antigens are naturally occurring alloantibodies found in plasma or serum of an individual lacking the corresponding antigen on red cells. The reciprocal relationship of these antibodies in serum to corresponding antigen on red cells help in confirming the ABO blood group of a person and warrants the use of homologous blood in transfusion.[1] RBC alloimmunization is the formation of antibody/ antibodies by the recipient to red blood cell antigens from previous transfusion or pregnancy. Occasionally RBC alloimmunization occurs without exposure to foreign RBC antigen; in this case presumably the stimulus

'Financial or Other Competing Interest': None.

Submission 15-11-2018, Peer Review 21-01-2019,

Acceptance 28-01-2019, Published 04-02-2019.

Corresponding Author:

Sonika Gupta,

House No. 281-A,

Vikram Nagar, Sarwal-180005,

Jammu, Jammu and Kashmir, India.

E-mail: sonikagupt@gmail.com

DOI: $10.14260 /$ jemds $/ 2019 / 65$

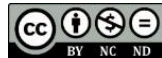

is from antigens located outside the RBC membrane or from other substances such as bacteria or viruses.

By now, over 250 blood group antigens with their corresponding antibodies have been identified and grouped into 29 systems: for example, Kell (With e.g. the antigens $\mathrm{K}$ and $\mathrm{k}$ ), rhesus ( $\mathrm{C}, \mathrm{c}, \mathrm{C}$,, $\mathrm{E}$ and e), Duffy (Fya and Fyb), Kidd (Jk and $\mathrm{Jk}^{\mathrm{b}}$ ), etc.[2] The population prevalence of these blood group antigens shows wide variation: for example, $9 \%$ for the $\mathrm{K}$ antigen, $99 \%$ for the $\mathrm{k}$ antigen, $83 \%$ for the $\mathrm{c}$ antigen, $65 \%$ for the $\mathrm{C}$ antigen and only $2 \%$ for the $\mathrm{Cw}^{\mathrm{w}}$ antigen in Caucasians. ${ }^{[3]}$ The incidence of alloantibodies varies widely according to patient disease, prior history of transfusion, pregnancy and the antigen frequencies of patients versus donors in a geographic location. The incidence of red cell antibodies is estimated to be $1-2 \%$ in general hospital population, $5 \%$ or more in multi-transfused patients and multiparous females, and $20 \%$ or more in patients with transfusion dependent diseases (e.g. sickle cell anaemia, thalassemia, etc).[4]

It is important to identify all RBC antibodies in pregnancy to determine whether there is a risk of haemolytic disease of newborn and to facilitate cross matching of maternal blood if an emergency transfusion is required at delivery. Though anti 
D continues to be the commonest cause, other blood group antibodies are also known to cause haemolytic disease of fetus and newborn (HDFN) and haemolytic transfusion reactions.[5] The individual blood antigens differ in their potency to induce an antibody response (Immunogenicity), listed in order of decreasing immunogenicity: D, K, E, c, Jk and Fy. Finally, additional variation exists in the ability to cause HDFN. HDFN severe enough to require treatment by antenatal intrauterine fetal transfusions and/or neonatal (Exchange) transfusions occurs in $2-4 \%$ of non-RhD immunized pregnancies. Anti-k, anti-c and to lesser extent other Rh antibodies ( $\mathrm{C}, \mathrm{Cw}, \mathrm{E}$ and e) cause severe HDFN in the vast majority of cases.[6] Consequent to the introduction of routine RhIG immunoprophylaxis, alloantibodies other than anti D have emerged as an important cause of HDFN and now responsible for greater proportion of these cases.[7]

Antenatal first trimester screening enables timely detection of alloantibodies and treatment of HDFN, and an additional benefit of the screening program is the detection of alloantibodies relevant in case of transfusion to the mother.

Most developed countries have guidelines for screening all pregnant women for irregular erythrocyte antibodies. According to the guidelines of the British committee for standards in Haematology, all pregnant women should be $\mathrm{ABO}$ and D antigen typed and screened for the presence of red cell antibodies early in pregnancy and at the $28^{\text {th }}$ week of gestation. ${ }^{[8]}$ According to guidelines in the Netherlands, it has been mandatory since 1998 to screen all pregnant women for the presence of irregular antibodies in the first trimester of pregnancy.[9]

However, no such guidelines are followed in developing countries like India. The present study is aimed to determine the percentage of RBC antibodies women as well as in general population.

\begin{tabular}{|c|c|}
\hline \multicolumn{2}{|c|}{$\begin{array}{c}\text { RBC Antibodies That May Be Associated with Moderate or } \\
\text { Severe HDFN }\end{array}$} \\
\hline Rhesus & $D, C, c, E$ \\
\hline Kell & $\mathrm{K}, \mathrm{k}$ \\
\hline Duffy & $\mathrm{Fy}^{3}$ \\
\hline Kidd & $\mathrm{Jk}^{\mathrm{a}}, \mathrm{Jk}^{\mathrm{b}}$ \\
\hline \multicolumn{2}{|c|}{ RBC Antibodies that may be associated with Mild HDFN } \\
\hline $\mathrm{ABO}$ & $\mathrm{A}, \mathrm{B}$ \\
\hline Rhesus & E \\
\hline Ii & I \\
\hline Duffy & Fyb \\
\hline Lutheran & $\mathrm{Lu}^{\mathrm{a}}, \mathrm{Lu}^{\mathrm{b}}$ \\
\hline \multicolumn{2}{|c|}{ RBC Antibodies not associated with HDFN } \\
\hline Lewis & Le $^{\mathrm{a}}, \mathrm{Le}^{\mathrm{b}}$ \\
\hline Ii & $\mathrm{I}$ \\
\hline $\mathrm{P}$ & $\mathrm{P}_{1}$ \\
\hline
\end{tabular}

\section{MATERIALS AND METHODS}

Ours was a Cross-sectional study. This study was planned to assess the prevalence of erythrocyte antibodies responsible for alloimmunisation in pregnant patients attending Manipal Hospital Bangalore and in patients referred for follow up and management during pregnancy (Antenatal care) and child birth and compare the prevalence with that of the other patients coming to the hospital. Maternal and perinatal outcome of those found positive was also studied. Study period was from Ist October 2012 to $30^{\text {th }}$ August 2013.

\section{Inclusion Criteria}

1. Antenatal patients presenting to the hospital.

2. Other patients from other departments on whom blood grouping and antibody screening has been done.

\section{Exclusion Criteria}

None.

For each patient, name, age, sex, obstetric history, blood group, history of having received anti-D immunoprophylaxis (In the current pregnancy) and history of blood transfusions was recorded prior to taking the blood samples. Blood samples were collected into EDTA vials and sent to the blood bank.

All the samples were centrifuged at 2, $000 \mathrm{rpm}$ for 5 minutes and plasma separated immediately and tested for grouping and presence of antibodies. ABO blood grouping and D typing was performed for each patient using the column gel agglutination technology according to the Regional Blood Transfusion Centre's Standard Operating Procedures. All ' $\mathrm{D}$ ' negative samples by tube method were confirmed for weak D by an indirect antiglobulin test and subsequently by column agglutination technology.

A commercially available three-cell antigen panel (ID DiaCell I, II, III; Diamed ID microtyping system, Diamed Switzerland) was used for the antibody screening procedure in which the patient's serum was reacted with red cells using low ionic strength saline (LISS) Coombs' gel card (With and without papain). The cards were incubated at $37^{\circ} \mathrm{C}$ for 15 minutes and then centrifuged for 10 minutes. If the antibody screen with the three-cell antigen panel was positive, an extended 11-cell panel was used for antibody identification in LISS with and without enzyme (Diamed 11 cell DiaPanel).

A review was conducted of the medical history, obstetric history (Including any still births, abortions, medical terminations of pregnancy and cases of HDFN among siblings) and any past blood transfusions of the alloimmunised patients. Pregnant women who were found antibody positive and titres above critical value had Doppler done every month till 28 weeks and then fortnightly till delivery. In women who were found to be antibody positive, neonatal blood sample was sent for $\mathrm{Hb}$, serum bilirubin, antibody titers etc.

\section{RESULTS}

$1030(12.68 \%)$ pregnant patients and 7098 (87.32\%) nonpregnant patients were screened for antibodies during this period with positivity of $3.3 \%(33 / 1030)$ in pregnancy and $0.87 \%(62 / 7098)$ in other patient population. In positive groups, average age of the pregnant patient was 30.27 yrs. (SD \pm .83 ) while that of non-pregnant patients were 37.91 yrs. (SD \pm 8.48). (Table Nos. 2 and 3).

\begin{tabular}{|c|c|}
\hline Age Group (Yrs.) & No. of Patients \\
\hline $21-30$ & $19(57.57 \%)$ \\
\hline $31-40$ & $14(42.42 \%)$ \\
\hline \multicolumn{2}{|c|}{ Table 2. Age Wise Distribution of Antibody Positive Cases } \\
in Pregnant Group
\end{tabular}




\begin{tabular}{|c|c|}
\hline Age Group (yrs.) & No. of Patients \\
\hline $0-10$ & $5(8.1 \%)$ \\
\hline $11-20$ & $6(9.7 \%)$ \\
\hline $21-30$ & $14(22.6 \%)$ \\
\hline $31-40$ & $9(14.5 \%)$ \\
\hline $41-50$ & $11(17.7 \%)$ \\
\hline $51-60$ & $8(12.9 \%)$ \\
\hline $61-70$ & $8(12.9 \%)$ \\
\hline $71-80$ & $1(1.61 \%)$ \\
\hline
\end{tabular}

Table 3. Age Wise Distribution of Antibody Positive Cases in Other Patient Groups

Anti D (27/33) was the predominant antibody found in $81 \%$ pregnant patients with anti E, Anti Lea in $6.7 \%$ (2 each) and anti $\mathrm{C}$ and anti $\mathrm{K}$ in $3.0 \%$ (1 each). Out of 27 anti D positive patients, 11 had received injection anti $\mathrm{D}$ within last few weeks. Anti D was positive in $17.7 \%(11 / 62)$ of the nonpregnant group followed by Anti Le $14.5 \%$ (9/62), anti M $11.3 \%$ (7/62) and anti E 9.7\% (6/62). (Table 4)

\begin{tabular}{|c|c|c|}
\hline Antibody Type & $\begin{array}{c}\text { Pregnant Group } \\
(\mathbf{n = 3 3 )}\end{array}$ & $\begin{array}{c}\text { Other Patients } \\
\text { Group (n=62) }\end{array}$ \\
\hline Anti D & $27(81.8 \%)$ & $11(17.7 \%)$ \\
\hline Anti C & $1(3.0 \%)$ & $3(4.8 \%)$ \\
\hline Anti E & $2(6.1 \%)$ & $6(9.7 \%)$ \\
\hline Anti K & $1(3.0 \%)$ & $3(4.8 \%)$ \\
\hline Anti Le & $2(6.1 \%)$ & $9(14.5 \%)$ \\
\hline Anti M & & $7(11.3 \%)$ \\
\hline Anti Fy & & $1(1.6 \%)$ \\
\hline Anti D+M & & $1(1.6 \%)$ \\
\hline Anti K+E & & $1(1.6 \%)$ \\
\hline Anti Jka & & $1(1.6 \%)$ \\
\hline Anti S & & $1(1.6 \%)$ \\
\hline Autoantibodies & & $15(24.2 \%)$ \\
\hline Indeterminate & & $2(3.2 \%)$ \\
\hline \multicolumn{2}{|c|}{ Table 4. Antibody Distribution in The Two Groups } \\
\hline
\end{tabular}

One of the patients with anti D antibodies with a twin pregnancy had twin transfusion and both twins expired after laser ablation where as one patient with anti Lea antibody required intrauterine transfusion for fetal anaemia which was diagnosed as caused by parvovirus. All other patients and their newborns in the positive group did not have any other significant morbidity.

\section{DISCUSSION}

This is one of the few studies reporting the prevalence of RBC alloantibodies in pregnant patients as well as general population (Attending the hospital). The incidence of anti RBC alloimmunization in general population was $0.87 \%$. Studies in various parts of the world have shown a varied incidence of RBC antibody due to difference in heterogeneity of population involved, varied screening protocols, variations in the definition of clinically significant antibody and difference in the technique used for antibody identification.

In western word Gottvall $\mathrm{T}$ et al.[10] reported the incidence of RBC antibody to be $0.37 \%$ in their study from Sweden whereas Jovanovic $S$ et al.[11] reported the incidence of potentially clinically significant antibody to be $2.4 \%$. In African world Natukunda B et al.[12] in their study from Uganda reported the incidence of RBC antibody in pregnant ladies to be $2.2 \%$ where as Jeremaih ZA et al.[13] reported the incidence to be $4.8 \%$ in their study from Nigeria. In studies conducted across India, Pahuja $S$ et al.[14] reported the incidence of alloimmunization to be $1.25 \%$ whereas Varghesh J et al.[15] in their study from Vellore reported the incidence to be $1.49 \%$.

Anti D (27/33) was the predominant antibody found in $81 \%$ pregnant allo antibody positive patients consistent with most of the studies with anti E, Anti Lea (2 each) and anti C and anti $\mathrm{K}$ in 1 each in our study. Pahuja S[14] et al. also reported anti $\mathrm{D}$ to be the major antibody contributing to $78.4 \%$ of the total alloimmunization and anti $\mathrm{C}$ to be $11.76 \%$

In a study conducted by Jovanovic $S$ et al.[11] the majority of allo antibodies belonged to the Rh system (anti D 40\% anti C 23\%, anti E 11\%) followed by anti-M (3.7\%), anti-Fya (0.9\%), anti-S (0.6\%), anti-JKa and anti Jk $\mathrm{K}^{\mathrm{b}}$. Among antibodies of no clinical significance, the most frequent were anti $\mathrm{H}$, antiLea, and anti- $\mathrm{P}_{1}$.

Varghese J et al. in their study found that out of 50 women whose antibodies were characterized, 32 (64\%) were found to have antibodies commonly associated with HDFN (Anti-D, c, E, e, C, K), four (8\%) had antibodies that are occasionally associated with HDFN (anti-Jka, Jkb, S, M) and 14 (28\%) had antibodies which are not known to cause HDFN (Lea, Leb). Anti-D can cause both a moderate and a severe form of HDN. The incidence of anti-D alloimmunization in $\mathrm{D}$ negative women without the administration of prophylactic anti-D during pregnancy is usually noted at the end of a second pregnancy with an incidence of 8 to $10 \%$, and after the fourth of fifth pregnancy, at $50 \%$ [11]. HDN caused by anti-C is usually mild as the $\mathrm{C}$ antigen has weak immunogenicity. Anti E can be naturally occurring or immune mediated. Immune form of anti $\mathrm{E}$ is able to cause mild to moderate HDN.

As compared to the incidence of $0.87 \%$ reported in the general population, the overall incidence of RBC alloimmunization in transfused patients have been reported to be $3.4 \%$ (18/531), with anti-C being the most common (38.8\%) followed by anti-E (22.2\%), anti-M (11.1\%), anti-Lea (11.1\%), anti-D (5.6\%), anti-Jk ${ }^{\mathrm{a}} \quad(5.6 \%)$ and anti-Le (5.6\%).[16]

\section{CONCLUSION}

The reported incidence of $\mathrm{RBC}$ antibody in pregnant patients has been much higher in our study as compared to previous studies. Despite prophylactic use of $\mathrm{Rh}$ immunoglobulins, anti-D is still a common antibody identified as the major cause of alloimmunisation. As Rh immunization due to anti D is preventable, measures need to be taken to prevent it. The incidence of non-Rh antibodies is also high especially in the non-pregnant group and this increasing trend may lead to increase in incidence of HDFN and transfusion related reactions in the future. Although there was no significant mortality or morbidity in pregnant women and their infants with RBC antibody, large-scale studies like this still need to be conducted to formulate effective guidelines.

\section{REFERENCES}

[1] Joshi SR, Vasantha K, Iyer YS, et al. Studies on the ABHIso-Agglutininis in serum, saliva and milk from mothers with "Bombay" (Oh) phenotype. Asian J Transfus Sci 2009;3(1):3-5.

[2] Daniels GL, Fletcher A, Garratty G, et al. Blood group terminology 2004: from the International Society of Blood Transfusion Committee on terminology for red cell surface antigens. Vox Sang 2004;87(4):304-16. 
[3] Reid ME, Lomas-Francies C. The Blood group antigen factsbook. $2^{\text {nd }}$ edn. San Diego, CA: Academic Press 2004.

[4] Red Cell Alloimmunization. www.transfusionmedicine.ca/book/export/html/311.

[5] Klein HG, Anster DJ. Mollison's blood transfusion in clinical medicine. 11 th edn. UK: Blackwell Publishing Ltd., 2005.

[6] Koelewijn JM, Vrijkotte TG, Van der Schoot CE, et al. Effect of screening for red cell antibodies, other than anti-D, to detect hemolytic disease of the fetus and newborn: a population study in the Netherlands. Transfusion 2008;48(5):941-52.

[7] Poole J, Daniels G. Blood group antibodies and their significance in transfusion medicine. Trans Med Rev 2007;21(1):58-71.

[8] British committee for standards in Hematology: Guidelines for blood grouping and red cell antibody testing during pregnancy. Jul, 2008.

[9] Semmekrot BA, De Man AJ, Boekkooi PF, et al. Irregular blood group antibodies during pregnancy: screening is mandatory. Ned Tijdschr Geneeskd 1999;143(28):1449-52.

[10] Gottvall T, Selbind A, Hidden JO. Evaluation of a new Swedish protocol for alloimmunication screening during pregnancy. Acta Obstet Gynecol Scand 1993;72(6):434-8.
[11] Jovanovic S, Djokic M, Tijanic N, et al. Antibodies detected in samples from 21, 730 pregnant women. Immuohematology 2003;19:89-92.

[12] Natukunda B, Mugyenyi G, Brand A, et al. Maternal red blood cell alloimmunization in South Western Uganda. Transfus Med 2011;21(4):262-6.

[13] Jeremiah ZA, Mordi A. Evaluation of the clinical utility of maternal alloantibody screening as a surrogate to antiglobulin crossmatch procedures in resource limited settings. International J Blood Trans and Immunohemat 2011;1:1-6.

[14] Pahuja S, Gupta SK, Pujani M, et al. The prevalence of 11 irregular erythrocyte antibodies among antenatal women in Delhi. Blood Transfus 2011;9(4):388-93.

[15] Varghese J, Chacko MP, Rajaiah M, et al. Red Cell alloimmunization among antenatal women attending a tertiary care hospital in south India. Indian J Med Res 2013;138(1):68-71.

[16] Thakral B, Saluja K, Sharma RR, et al. Red cell alloimmunization in a transfused patient population: a study from a tertiary care hospital in north India. Hematology 2008;13(5):313-8. 